\title{
Carotid artery intima-media thickness in patients with acute ischemic stroke and its correlation with risk factors for atherosclerosis and/or stroke
}

\author{
Shovan Kumar Das', Amit Sarkar², Subhraprakash Pramanik ${ }^{3}$, Amitabha Bandyopadhyay ${ }^{4}$, \\ Koushik Mondal ${ }^{5}$, Sanjai Kumar Singh ${ }^{5}$
}

${ }^{1}$ Medical Officer (Physician), Sub-Divisional Hospital, Ghatal, West Midnapore, West Bengal, India, ${ }^{2}$ Residential Medical Officer cum Clinical Tutor (presently posted as - Assistant Professor), ${ }^{3}$ Senior Resident, ${ }^{4}$ Associate Professor, ${ }^{5}$ Postgraduate Trainee, Burdwan Medical College, Burdwan, West Bengal, India

\section{A B S T R A C T}

Introduction: Stroke is the second leading cause of mortality worldwide. Ischemic stroke is more prevalent than hemorrhagic stroke and atherosclerosis is the major cause of ischemic stroke. The increased carotid artery intima-media thickness (CIMT) is considered to be useful indicator of early atherosclerosis. So, this study was aimed to correlate the relationship between atherosclerotic risk factors and intima-media thickness of carotid artery in patients with acute ischemic stroke. Material and Methods: In this cross-sectional study, 100 consecutive patients of acute ischemic stroke and 50 healthy relatives of patients as control were studied for presence of atherosclerotic risk factors and carotid artery intima-media thickness by B-mode Doppler ultrasonography. Results: In this age and sex matched study, higher CIMT measurement was found among patients of acute ischemic stroke than healthy controls $(0.849 \pm 0.196$ vs $0.602 \pm$ $0.092 ; \mathrm{p}<0.001)$. The CIMT was well correlated with smoking (Beta $=0.295 ; \mathrm{t}=5.728$; $95 \% \mathrm{Cl} 0.088$ to $0.181 ; \mathrm{p}<0.001$ ); hypertension (Beta $=0.387 ; \mathrm{t}=6.518 ; \mathrm{Cl} 0.112$ to $0.209 ; \mathrm{p}<0.001)$; di abetes (Beta $=0.237 ; \mathrm{t}=4.848 ; \mathrm{Cl} 0.074$ to $0.175 ; \mathrm{p}<0.001$ ); hypercholesterolemia (Beta $=0.292 ; \mathrm{t}=5.840 ; \mathrm{Cl} 0.096$ to $0.195 ; \mathrm{p}<0.001$ ), but not with age ( $p=0.153)$. The CIMT was also found to be higher among acute ischemic stroke patients who were smoker, hypertensive, diabetic and hypercholesterolemic than non-smoker, normotensive, non-diabetic and normo-cholesterolemic respectively. Conclusion: The CIMT being indicator of atherosclerosis can be used as future predictor of ischemic stroke.

Key words: Ischemic stroke, Atherosclerotic risk factors, Carotid artery intima-media thickness

\section{INTRODUCTION}

Stroke is the second leading cause of mortality worldwide. ${ }^{1}$ It remains the leading cause of serious long-term morbidity. ${ }^{2}$ According to the estimates by the National Commission on Macroeconomics and Health, in India there will be 1.67 million stroke cases in $2015 .^{3}$ The cost of stroke is in billions of rupees every year which include treatment, rehabilitation and productivity loss of stroke survivors. The cost in terms of pain and suffering of patients and their families is immeasurable. The available data indicate that stroke occurring in young people is
Access this article online

Website:

http://nepjol.info/index.php/AJMS 


\section{MATERIALS AND METHODS}

\section{Study site}

This cross-sectional study was done at our institution during the period from March, 2011 to February, 2012. This institution is tertiary referral centre for patients of neighbouring seven districts and part of neighbouring State. All participants were provided with written informed consent and the study protocol was approved by the Ethical Committee of the institution.

\section{Cases}

The study subjects include consecutive 100 patients with acute ischemic stroke who were admitted in the hospital for treatment. The patients who qualified WHO definition of stroke as "rapidly developing clinical signs or focal (or global) disturbances of cerebral function lasting for more than 24 hours (unless interrupted by surgery or death) with no apparent cause other than of vascular origin", presented within 5 days of first symptoms and diagnosed cerebral infarction by either computed tomography scan or magnetic resonance imaging were included in this study. Exclusion criteria were previous history of cerebro or cardiovascular events (cerebral ischemia or hemorrhage, ischemic heart disease or acute myocardial infarction), renal failure, valvular heart disease, atrio-ventricular block, atrial fibrillation and patients on drugs like statins, aspirin, angiotensin converting enzyme inhibitor, angiotensin receptor blocker.

\section{Controls}

The control subjects were 50 healthy age and sex matched relatives and friends of stroke patients. In control group, all participants were non-smoker, non-hypertensive, non-diabetic and with normal lipid levels.

\section{Defining risk factors}

The criteria for presence of risk factors are as follows: (1) Hypertension - if measured blood pressure was $\geq 140 / 90 \mathrm{mmHg}$ on two occasions and/or treated for hypertension before stroke; (2) Diabetes Mellitus - if presented with a history of diabetes mellitus and/or were on diet control, hypoglycemic drugs or received insulin treatment or had random blood sugar $>200 \mathrm{mg} \%$ during hospital stay; (3) Smoking - 'Smoker' group comprises ever smoker, current smoker and ex-smoker. An 'ever smoker' was defined as a person who self-reported smoking at least 100 cigarettes during the course of his/her lifetime or having smoked pipes or cigars for six months or more. A "current smoker" was defined as a person who self-reported smoking within the calendar year prior to the year of diagnosis while an "ex-smoker" was defined as an ever smoker who had quit smoking for more than one calendar year prior to the diagnosis year. ${ }^{7}$ Non-smoker' group was defined as a person who didn't meet the criteria for ever smoker, current smoker or ex-smoker; (4) Hypercholesterolemia - considered when a patient who had a diagnosis of it and/or was on prescribed diet or lipid lowering agents or had fasting cholesterol $>200 \mathrm{mg} / \mathrm{dl}$ during hospital stay.

\section{Data collection}

For cases, using a structured proforma we abstracted demographic, clinical and investigative data from records. The blood pressure, fasting glucose and fasting lipid examination was done at approximately a week or later after stroke onset, as elevated blood pressure, hyperglycemia and lower blood lipids are well documented findings during acute phase of stroke. Blood glucose and cholesterol were estimated on automated systems with standardized kits using enzymatic methods for both cases and controls. The CIMT was measured with a duplex ultrasound system in the B-mode (Phillip's HD-7 with CW and PW option) with linear transducer of $7.5 \mathrm{MHz}$ based on technique validated by Pignoli et al. ${ }^{8}$ The longitudinal view of the normal carotid wall demonstrates two parallel echogenic lines, separated by a hypoechoic to anechoic region. The first echoic line bordering the vessels lumen representing the lumen-intima interface; the second echoic line is caused by the media-adventitia interface. The distance between these two lines-represents the intima-media thickness of the carotid. ${ }^{9}$ The IMT measurement of both right and left sides of the carotid bifurcation, internal carotid and common carotid arteries were taken. The mean value of above six sites was used for analysis.

\section{Statistical analysis}

All data were analysed by standard statistical methods using SPSS software, 20th version. The student' t-test for continuous variables, chi-square test for categorical variables and simple regression analysis for correlation was used for statistical comparison. The $\mathrm{p}$ value $<0.05$ was considered as statistically significant for all tests.

\section{RESULTS}

On comparing, mean age and gender distribution between case and control groups showed no significant difference (Table 1). Among the 100 cases of ischemic stroke and 50 controls, mean CIMT values showed significant differences (Table 2). The risk factors for stroke affecting CIMT were analysed by simple regression analysis and it showed that the CIMT correlated positively with smoking, hypertension, diabetes mellitus and hypercholesterolemia, but not with age (Table 3). The ischemic stroke patients with presence of risk factors such as smoking, hypertension, diabetes mellitus, and hypercholesterolemia presented with significantly higher CIMT values than patient with absence of risk factors (Table 4). 


\section{DISCUSSION}

In Western countries, coronary heart disease (CHD) is more common than stroke, whereas in Asian-pacific countries, stroke outnumbers CHD. ${ }^{10}$ More than two-thirds

\begin{tabular}{|c|c|c|c|c|c|}
\hline & $\begin{array}{c}\text { Total } \\
\text { number }\end{array}$ & $\begin{array}{c}\text { Mean } \\
\text { age (Yrs) }\end{array}$ & $\begin{array}{l}\text { Standard } \\
\text { deviation }\end{array}$ & $\begin{array}{l}\text { Std. error } \\
\text { of mean }\end{array}$ & $P$ value \\
\hline \multicolumn{6}{|l|}{ Age } \\
\hline Case & 100 & 57.21 & 7.711 & 0.771 & $0.64^{*}$ \\
\hline \multirow[t]{2}{*}{ Control } & 50 & 54.76 & 7.493 & 1.060 & \\
\hline & & \multicolumn{3}{|c|}{ Number/out of total number } & $P$ value \\
\hline \multicolumn{6}{|l|}{ Sex } \\
\hline \multirow[t]{2}{*}{ Male } & Case & & $64 / 100$ & & $0.809^{* *}$ \\
\hline & Control & & $33 / 50$ & & \\
\hline \multirow[t]{2}{*}{ Female } & Case & & $36 / 100$ & & \\
\hline & Control & & $17 / 50$ & & \\
\hline
\end{tabular}

\begin{tabular}{|c|c|c|c|c|c|}
\hline & Number & $\begin{array}{c}\text { Mean } \\
\text { CIMT }(\mathrm{mm})\end{array}$ & $\begin{array}{l}\text { Standard } \\
\text { deviation }\end{array}$ & $\begin{array}{l}\text { Std error } \\
\text { of mean }\end{array}$ & $P$ value \\
\hline \multicolumn{6}{|l|}{ CIMT } \\
\hline Case & 100 & 0.8492 & 0.19646 & 0.01965 & $<0.001$ \\
\hline Control & 50 & 0.6018 & 0.09244 & 0.01307 & \\
\hline
\end{tabular}

of the global burden of stroke is borne by developing countries, where the average age of patients with stroke is 15 years younger than that of developed countries. ${ }^{11}$ In India the incidence of stroke is likely to increase in the coming years due to: a) increase in population; b) increase in life expectancy; c) rapid urbanization from migration of village population to cities; d) changing life styles involving sedentary habits, smoking, excess alcohol use etc.; e) rising stress level in life. ${ }^{12}$ Non modifiable risk factors for stroke include increasing age, sex, race/ethnicity, family history, genetic factors and low birth weight. Well documented risk factors that clearly benefit from specific management include hypertension, cigarette smoking, atrial fibrillation, dyslipidemia, diabetes mellitus and asymptomatic carotid stenosis. The other well documented risk factors are cardiovascular and peripheral arterial disease, sickle cell disease and obesity. Less well documented or potentially modifiable risk factors include metabolic syndrome, hyperhomocysteinemia, hypercoagulability, oral contraceptive use, inflammatory process, migraine headache and sleep apnoea. ${ }^{13}$ The results of previous hospital based studies suggest that ischemic stroke is polyetiologic disturbances. The synergistic action of hypertension, diabetes mellitus and hyperlipidemia predisposes patient for lacunar stroke. The current treatment for patient with established stroke is relatively ineffective and it is important to identify the risk factors of stroke in a particular patient

\begin{tabular}{|c|c|c|c|c|c|c|c|}
\hline \multirow[t]{2}{*}{ Model } & \multicolumn{2}{|c|}{$\begin{array}{l}\text { Unstandardized } \\
\text { coefficients }\end{array}$} & \multirow{2}{*}{$\begin{array}{c}\text { Standardized } \\
\text { coefficients } \\
\text { Beta }\end{array}$} & \multirow[t]{2}{*}{$\mathbf{t}$} & \multirow[t]{2}{*}{$\begin{array}{c}\text { Sig. } \\
\text { ( } p \text { value) }\end{array}$} & \multicolumn{2}{|c|}{$\begin{array}{l}95 \% \text { confidence } \\
\text { interval for B }\end{array}$} \\
\hline & B & Std. error & & & & Lower & Upper \\
\hline Constant & 0.435 & 0.106 & & 4.117 & $<0.001$ & 0.226 & 0.644 \\
\hline Age & 0.003 & 0.002 & 0.114 & 1.438 & 0.153 & -0.001 & 0.007 \\
\hline Smoking & 0.134 & 0.023 & 0.295 & 5.728 & $<0.001$ & 0.088 & 0.181 \\
\hline Hypertension & 0.160 & 0.025 & 0.387 & 6.518 & $<0.001$ & 0.112 & 0.209 \\
\hline Diabetes & 0.125 & 0.026 & 0.237 & 4.848 & $<0.001$ & 0.074 & 0.175 \\
\hline Hypercholesterolemia & 0.146 & 0.025 & 0.292 & 5.840 & $<0.001$ & 0.096 & 0.195 \\
\hline
\end{tabular}

\begin{tabular}{|c|c|c|c|c|c|}
\hline Risk factors & No of cases/out of total & Mean CIMT (mm) & Standard deviation & Std. error of mean & $P$ value \\
\hline \multicolumn{6}{|l|}{ Smoking } \\
\hline Yes & $32 / 100$ & 1.0166 & 0.11614 & 0.02053 & \multirow[t]{2}{*}{$<0.001$} \\
\hline No & $68 / 100$ & 0.7704 & 0.17639 & 0.02139 & \\
\hline \multicolumn{6}{|l|}{ Hypertension } \\
\hline Yes & $62 / 100$ & 0.9737 & 0.11565 & 0.01619 & \multirow[t]{2}{*}{$<0.001$} \\
\hline No & $38 / 100$ & 0.7196 & 0.17901 & 0.02557 & \\
\hline \multicolumn{6}{|c|}{ Diabetes mellitus } \\
\hline Yes & $22 / 100$ & 1.0205 & 0.11627 & 0.02479 & \multirow[t]{2}{*}{$<0.001$} \\
\hline No & $78 / 100$ & 0.8009 & 0.18760 & 0.02124 & \\
\hline \multicolumn{6}{|c|}{ Hypercholesterolemia } \\
\hline Yes & $27 / 100$ & 1.0278 & 0.10127 & 0.01949 & \multirow[t]{2}{*}{$<0.001$} \\
\hline No & $73 / 100$ & 0.7832 & 0.18161 & 0.02126 & \\
\hline
\end{tabular}


and to be aware that prevention i.e. timely identification and therapy for stroke risk factors is the most efficacious method of stroke treatment. ${ }^{14}$ Of all stroke, approximately $70 \%$ are first time events, thus physicians have a great opportunity to identify patient who may benefit from risk factor modification. The ischemic stroke is mostly caused by abrupt interruption of blood supply and irreversible damage to brain tissue. The mechanism of the arterial occlusion varies from cardiogenic embolus to degenerative disease of small diameter penetrating arteries. Of the various mechanisms, in-situ atherosclerosis with superimposed occluding thrombosis and artery to artery embolization are thought to be common. The common noninvasive marker of sub-clinical and clinical atherosclerosis include ankle brachial pressure index (ABPI), CIMT, aortic intima medial thickness (AoIMT), flow mediated brachial artery dilatation and the number and volume of carotid plaque. ${ }^{15}$ The CIMT serves as a marker of generalized atherosclerosis and it has been positively associated with CAD and stroke of all types. ${ }^{16} \mathrm{~A}$ CIMT of less than $0.55 \mathrm{~mm}$ have been found to be excellent marker of the absence of macrovascular abnormalities, especially coronary artery disease. ${ }^{15}$ A CIMT greater than $1 \mathrm{~mm}$ is almost certainly indicative of atherosclerosis and increased risk of cardiovascular disease. ${ }^{17}$ The carotid wall thickening as measured in this study is not the cause of ischemic stroke. With rare exception, CIMT represents neither an ulcerated plaque nor a haemo-dynamically significant lesion. CIMT is noncasual (surrogate) marker of many significant lesions elsewhere.

In this present study, mean CIMT of the study group was $0.849 \mathrm{~mm}$, which is almost similar to other Indian study like Sahoo et al $(0.792 \mathrm{~mm})$ and Mukherjee et al $(0.66 \mathrm{~mm})$, but western studies reported higher values. ${ }^{5,18}$ Cupin et al from Italy reported that mean CIMT in nonlacunar stroke and lacunar stroke patient was $1.04 \mathrm{~mm}$ and $0.91 \mathrm{~mm}$ respectively. ${ }^{19}$ Sau et al found that the CIMT is higher among dyslipidemic group $(1.71 \pm 0.57 \mathrm{~mm})$ compared to non-dyslipidemic group ( 0.77 $\pm 0.10 \mathrm{~mm}$ ) in patients with type 2 diabetes mellitus. ${ }^{20}$ They also observed that CIMT has positive correlation with higher blood levels of $\mathrm{HbA1C}$, total cholesterol, triglyceride, LDL-C, VLDL-C and negative correlation with HDL-C. Moreover, the CIMT was better correlated with LDL/HDL-C and total cholesterol/HDL-C than individual values of total cholesterol, triglyceride, LDL-C, VLDL-C. The male diabetic and prediabetic are more prone to have higher CIMT values than their non-diabetic counterparts irrespective of stroke type. ${ }^{21}$ Mohan et al and Lorenz et al showed CIMT of all varieties of stroke were significantly higher than nonstroke controls. ${ }^{22,23}$ One of the earlier reports from Salonen et al with data on 100 subjects, indicated that increasing age, LDL-cholesterol, pack-year of smoking showed the strongest relationships with 2 Year progression of CIMT. ${ }^{24}$
In contrast, blood pressure levels and HDL cholesterol were not related to progression of CIMT. But in our study, patients with high blood pressure had higher CIMT values. The Atherogene study among 502 subjects with suspected $\mathrm{CAD}$ indicated that age, male gender and current smoking were determinants of CIMT progression over a period of 2.5 year. ${ }^{25}$ The Atherosclerosis Risk in communities Study reported diabetes, current smoking, HDL cholesterol and pulse pressure to be positively related to increased progression of CIMT from 1987 to $1998 .{ }^{26}$ Rotterdam Study indicated that moderate to severe progression of common CIMT was related to age, BMI, male gender, current smoking, systolic blood pressure and hypertension. Lipid levels, however were not related to increased progression of common CIMT. ${ }^{27}$ In this present study hypercholesterolemia is positively correlated with CIMT. Davis et al found significant risk factors for increased CIMT were elevated LDL cholesterol and smoking in men and elevated LDL cholesterol and blood pressure in women. ${ }^{28}$ The CIMT increases as number of risk factors for stroke increases. ${ }^{29}$ Increased CIMT seems to be a predictive factor for stroke.

The CIMT estimated by 2-dimensional ultrasonography does not measure medial and intimal thickness separately and therefore cannot distinguish between medial remodeling as a result of an adapted response to tensile or hypertensive stress and intimal thickening which is primarily indicative of atherosclerosis. ${ }^{30}$ Whether CIMT increment is a modifiable risk factor with improved survival benefit, is still not known. ${ }^{21,31}$ There are several advantages to using CIMT testing: a) completely noninvasive; b) relative comfort and convenience for the patient being examined; c) does not involve radiation; d) lower cost and e) has the psychological advantages of an imaging tool for atherosclerosis, as patients and physicians tend to believe in visible structures rather than abstract concepts. The CIMT itself may not play a direct role in ischemic stroke and it can be considered an intermediate factor in the causal pathway between clinical risk factors and stroke. A large proportion of cardio and cerebrovascular events including sudden cardiac death in the general population occur in previously asymptomatic subjects and are often unanticipated. This highlights the necessity to close the gaps that are left between risk assessment with traditional risk factors and the real event risk. The CIMT, as a biomarker halfway between risk factors and organ damage, has raised hopes of bridging this gap.

Our study had several potential limitations. First; the number of incident cases of stroke was relatively small. Second, the study was conducted at tertiary care referral centre and may therefore be biased towards more severe form of disease. Third, use of community based population rather than cross-sectional design could reduce the possibility of selection bias. Although this study did 
not produce any new or surprising results, the value of Rural Medical College based studies like this one lies in strengthening the awareness of influencing risk factors for stroke prevention. Nonetheless, our findings added to the exiting literature about the role of CIMT measurement in predicting atherosclerosis and stroke.

\section{ACKNOWLEDGEMENTS}

All authors are thankful to the concerned patients, their relatives and friends for their written consent to conduct this study.

\section{REFERENCES}

1. Bilic I, Dzamonja G, Lusic I, Matijaca M and Caljkusic K. Risk factors and outcome differences between Ischemic and hemorrhagic stroke. Acta Clin Croat 2009.48:399-403.

2. Mishra N K and Khadilkar S V. Stroke program for India. Ann Indian Acad Neurol [serial Online] 2010 [cited 2012 Sep 29];13:28-32. Available from: http://www.annalsofian. org/text.asp?2010/13/1/28/61273

3. Workshop report on Stroke surveillance in India. Division of Noncommunicable Diseases, Indian council of Medical Research, New Delhi, India.[online ]13-15 th November,2006. Available from: URL: http://www.abpetta.com/REPORT_FILES/ SL36.pdf (Accessed on 30.03.2014).

4. Nayak S D, Nair M, Radhakrishnan K and Sharma PS. Ischaemic stroke in the young adult: clinical features, risk factors and outcome. Natl Med J India 1997;10: 107-112.

5. Mukherjee S C, Basu A K, Bandyopadhyay R, Pal S K, Bandyopadhyay D, Mandal S K, et al. Correlation of Lipid Profile and Carotid Artery Plaque as Detected by Ultrasound in ischemic Stroke Patients. A Hospital -based Study. J Indian Med Assoc 2006; 104: 325-326.

6. Banerjee T K, Mukherjee C S and Sarkhel A. Stroke in the urban population of Calcutta - an Epidemiological Study. Neuroepidemiology.2001; 20: 201-207.

7. Lin Li, Walter J Psoter, Carmen J Buxó, Augusto Elias, Lumarie Cuadrado and Douglas E Morse. Smoking and drinking in relation to oral potentially malignant disorders in Puerto Rico: a case-control study. BMC Cancer 2011; 11:324

8. Pignoli P, Tremoli E, Poli A, Oreste P and Paoletti. Intimal plus medial thickness of the arterial wall: a direct measurement with ultrasound imaging. Circulation 1986;74:1399-1406.

9. Raggi $P$ and Bellasi $A$. Review: Imaging to assess effect of medical therapy in patients with diabetes mellitus. $\mathrm{Br} \mathrm{J}$ Diabetes Vasc Dis 2007; 7: 157-164.

10. van den Hoogen P C, Feskens E J, Nagelkerke N J, Menotti A, Nissinen A and Kromhout D. The Relation between Blood Pressure and Mortality Due to Coronary Heart Disease among Men in Different Parts of the World. Seven Countries Study Research Group. N Engl J Med 2000; 342: 1-8.

11. Truelsen $\mathrm{T}$, Bonita $\mathrm{R}$ and Jamrozik K. Surveillance of stroke: a global perspective. Int J Epidemiol 2001; 30: S11-S16.

12. Prasad K and Singhal K K. Stroke in young: An Indian Perspective. Neurol India [Serial online]2010 [cited 2014 Apr 6]; 58: 343-350. Available from: http://www.neurologyindia.com/ text.asp?2010/58/3/343/65531.

13. Goldstein $L$ B, Adams $R$, Alberts $M J$, Appel L J, Brass L M, Bushnell C D, et al. AHA/ASA Guideline. Primary Prevention of Ischemic Stroke. A Guideline From the American Heart Association/American Stroke Association Stroke Council: Cosponsored by the Atherosclerotic Peripheral Vascular Disease Interdisciplinary Working Group; Cardiovascular Nursing Council; Clinical Cardiology Council; Nutrition, Physical Activity, and Metabolism Council; and the Quality of Care and Outcomes Research Interdisciplinary Working Group: The American Academy of Neurology affirms the value of this guideline. Stroke 2006; 37: 1583-1633.

14. Adams H, Adams R, Del Zoppo G and Goldstein LB. AHA/ASA Scientific Statement. Guidelines for the Early Management of Patients With Ischemic Stroke: 2005 Guideline Update: A Scientific Statement From the Stroke Council of the American Heart Association/American Stroke Association. Stroke 2005; 36: 916-923.

15. Belhassen L, Carville C, Pelle G, Monin J L, Teiger E, DuvalMoulin AM, et al. Evaluation of carotid artery and aortic intimamedia thickness measurements for exclusion of significant coronary atherosclerosis in patients scheduled for heart valve surgery. J Am Coll Cardiol 2002; 39(7): 1139-1144.

16. Chambless L E, Folsom A R, Clegg LX, Sharrett A R, Shahar E, Nieto F J, et al. Carotid Wall Thickness is Predictive of Incident Clinical Stroke: The Atherosclerosis Risk in Communities (ARIC). Am J Epidemiol 2000; 151(5): 478-487.

17. Feinstein $S B$, Voci $P$ and Pizzuto F. Non-invasive surrogate markers of atherosclerosis. Am J Cardiol 2002; 89 (5) 1: 31-43.

18. Sahoo R, Krishna M V, Subrahmaniyan D, Dutta $T K$ and Elangovan S. Common carotid intima-media thickness in acute ischemic stroke: A case control study. Neurol India 2009; 57: 627-630.

19. Cupini L M, Pasqualetti P, Diomedi M, Vernieri F, Silvestrini M, Rizzato B, et al. Carotid Artery Intima-Media Thickness and Lacunar Versus Nonlacunar Infarcts. Stroke 2002; 33: 689-694.

20. Sau T J, Dey S K, Chatterjee A, Kumar A and Biswas U K. Common carotid artery intima-media thickness reflects the cumulative burden of atherosclerosis and predicted well by total cholesterol/HDL-C ratio in Type II Diabetic Patients - A case controlled study based from Kolkata, India. Asian Journal of Medical Science 2014; 5(1)9-14.

21. Khealani B A, Syed N A, Maken S, Mapari U U, Hameed B, Ali $S$, et al. Predictors of ischemic versus hemorrhagic strokes in hypertensive patients. J Coll Physicians Surg Pak 2005; 15:22-25.

22. Mohan V, Ravikumar R, Shanthi Rani S and Deepa R. Intimal media thickness of the carotid artery in South Indian diabetic and nondiabetic subjects: the Chennai Urban Population Study (CUPS). Diabetologia 2000; 43(4): 494-499.

23. Lorenz $M$ W, von Kegler $S$, Steinmetz $H$, Marcus $H S$ and Sitzer M. Carotid Intima-Media Thickening Indicates a Higher Vascular Risk across a Wide Age Range: Prospective Data From the Carotid Atherosclerosis Progression Study (CAPS). Stroke 2006; 37: 87-92.

24. Salonen R and Salonen JT. Progression of carotid atherosclerosis and its determinants: a population-based ultrasonography study. Atherosclerosis 1990; 81: 33-40.

25. Espinola-Klein C, Rupprecht H-J, Blankenberg S, Bickel C, Kopp H, Victor A, et al. Impact of Infectious Burden on Progression of Carotid Atherosclerosis. Stroke 2002; 33: 2581-2586.

26. Chambless L E, Folsom A R, Davis V, Sharrett R, Heiss G, Sorlie $\mathrm{P}$, et al. Factors for Progression of Common Carotid Atherosclerosis: The Atherosclerosis Risk in Communities Study, 1987-1998. Am J Epidemiol 2002; 155(1): 38-47.

27. van der Meer I M, Iglesias del Sol $A$, Hak A E, Bots $M L$, Hofman A and Witteman JCM. Risk Factors for Progression of Atherosclerosis Measured at Multiple Sites in the Arterial Tree: The Rotterdam Study. Stroke 2003; 34: 2374-2379. 
28. Davis P H, Dawson J D, Mahoney L T and Lauer R M. Increased Carotid Intimal-Medial Thickness and Coronary Calcification Are Related in Young and Middle-Aged Adults: The Muscatine Study. Circulation 1999; 100: 838-842.

29. Urbina E M, Srinivasan S R, Tang R, Bond M G, Kieltyka L and Berenson G S. Impact of Multiple coronary risk factors on the intima-media thickness of different segments of carotid artery in healthy young adults (The Bogalusa Heart Study). Am J Cardiol 2002; 90(9): 953-958.
30. Johnsen S H and Mathiesen E B. Carotid Plaque compared with intima-media thickness as a predictor of coronary and cerebrovascular disease. Curr Cardiol Rep 2009; 11(1): 21-27.

31. Yanase T, Nasu S, Mukuta Y, Shimizu Y, Nishihara T, Okabe T, et al. Evaluation of a New Carotid Intima-Media Thickness Measurement by B-Mode Ultrasonography Using Innovative Measurement software, intimascope. Am J Hypertens 2006; 19(12): 1206-1212.

\section{Authors Contribution:}

SKD - Concept, design of study, definition of intellectual content, literature search, Clinical studies, Statistical analysis, manuscript preparation; AS - definition of intellectual content, literature search, manuscript preparation; SPP - definition of intellectual content, literature search, statistical analysis, manuscript revision; AB - Concept, design of study, definition of intellectual content, manuscript revision; KM - literature search, clinical studies, participated in the data and sample collection, manuscript revision; SKS - literature search, clinical studies, participated in the data and sample collection, manuscript revision.

Source of Support: Nil, Conflict of Interest: None declared. 